\title{
Unusual Pattern of Rt. Renal Artery and Supernumerary Lt. Renal Arteries: A Case Study
}

\author{
Dr. D. Asha latha M.D., Dr. Deena usha, Dr. Durga prasada rao, M.S., D.Ch., , \\ Dr. Hema Radhika, Dr. Sushma.M. \\ Department of Anatomy, Andhra Medical College, Visakhapatnam.
}

\begin{abstract}
Supernumerary renal arteries are more common on left side. Multiple renal arteries have an incidence of 15-30\%. Renal vasculature develops from three primitive vascular groups that coalesce to form the mature vascular pattern for all retroperitoneal structures. We are demonstrating an early bifurcation of right renal artery and the branches forming a loop around the inferior vena cava (IVC) which is an unusual pattern and multiple renal arteries (three) arteries supplying the left kidney. Patient is asymptomatic.
\end{abstract}

Key Words: Renal artery, Inferior vena cava, right kidney, Supernumerary renal arteries, left kidney.

\section{Introduction}

Renal arteries arise from abdominal Aorta and supplies the corresponding side of the kidney. Developmentally renal vasculature develops from three primitive vascular groups. During ascent of kidney, due to failure of degeneration of preliminary renal arteries, persistence of one or more supernumerary arteries is possible.

\section{Case Report}

M.Krishna Murthy Raju of 72 yrs, has donated his body after his demise. His body received after demise is embalmed and kept for dissection purpose. During routine dissection, for MBBS students in department of Anatomy, Andhra Medical College in his body we found the right renal artery arising from abdominal aorta almost at the level of superior mesenteric artery (SMA) and passing across the right crus of the diaphragm for distance of $2 \mathrm{~cm}$ and then divided into anterior and posterior branches forming a loop around the inferior vena cava (IVC) and then entered the renal pelvis behind the renal vein. Ureter is at lower position of pelvis. And on left side, we found three arteries supplying the left kidney. The cranial end one is of good caliber arising from Aorta and is supplying through pelvis of the kidney. Middle one is of moderate caliber and is arising from Aorta and is supplying through pelvis. The caudal one is of good caliber arising from Aorta and supplying the lower pole. The corresponding veins on the left side showed usual drainage except the caudal vein, which is draining into left common iliac vein.

\section{$\underline{\text { Image } 1 \& 2}$}

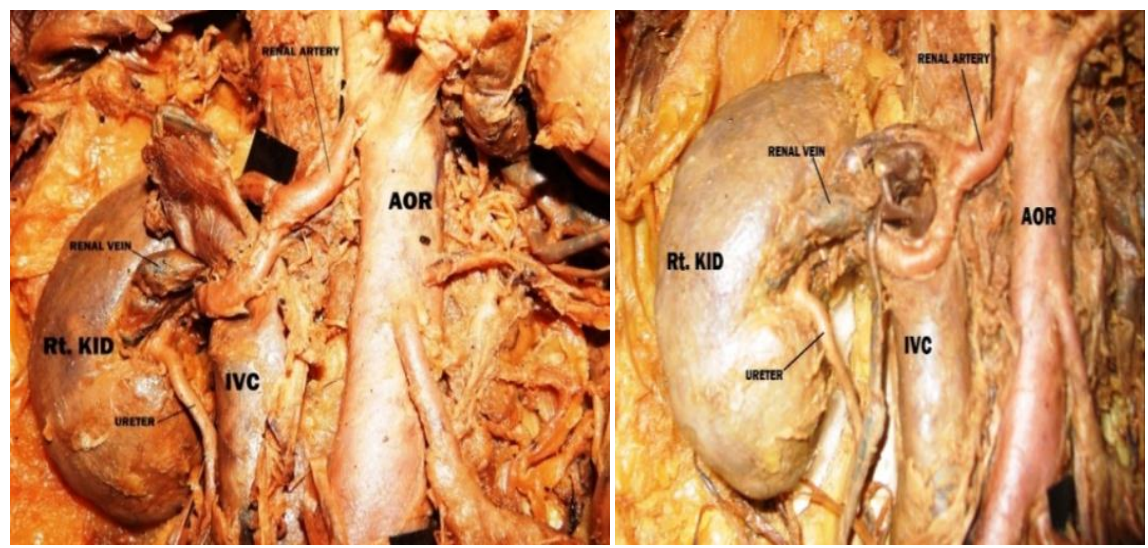

Image 1: rt renal artery showing early bifurcation. AOR-aorta, IVC-inferior vena cava, Rt. KID-Right Kidney. Image 2: rt renal artery forming a loop around IVC. . AOR-aorta, IVC-inferior vena cava, Rt. KID-Right Kidney. 


\section{Images $3 \& 4$}
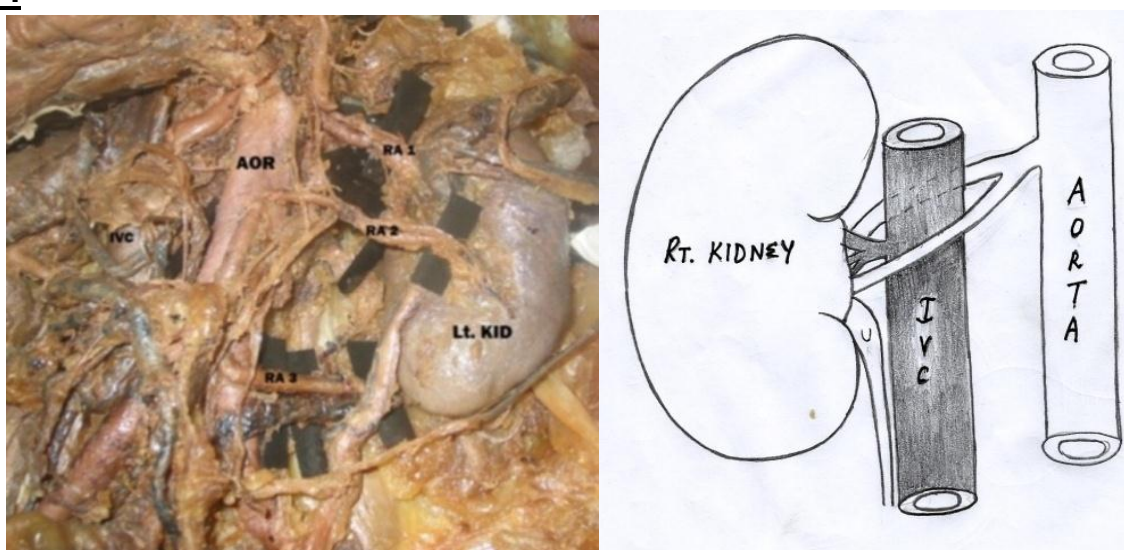

Image 3: Left kidney showing supernumerary renal vessels. AOR-aorta, RA 1 - renal artery 1, RA 2 - renal artery 2, RA 3-renal artery 3, all arising at different levels from aorta. IVC-inferior vena cava, Lt.KID - left kidney.

Image 4: Shematic representation of image $1 \& 2$, showing the right renal artery looping around Inferior Vena Cava. IVC - inferior vena cava.

\section{Results And Discussion}

Normally kidney is supplied by single renal artery that arises from aorta at level of L2 vertebra. At pelvis renal arteries divide into anterior and posterior branches and supplies the parenchyma. Developmentally kidney gets its vasculature from three groups of primitive vasculature which coalesce to form mature vascular pattern. Between six \& nine months of intra uterine period kidney ascends to a lumbar position just below adrenal glands. As the kidneys migrate they are vascularised by a succession of transient Aortic sprouts. These arteries do not elongate but degenerate and replaced by successive new arteries. The final pair of arteries forms in the upper Lumbar region and become definite renal arteries. These preliminary arteries if fail to degenerate and persist, leading to supernumerary arteries.

Renal arteries are end arteries and supernumerary arteries also share the same features. During surgical procedures if the renal artery is divided, it leads to infarction of the parenchyma. Presence of multiple renal arteries poses problem during renal transplantation and surgical procedures. Hydronephrosis, where in obstruction to outflow to ureter may be due to multiple renal vessels. For Hydronephrosis, due to supernumerary vessels, a surgical procedure by name Hamilton Stewart is done where in the renal vessels are made to slip out through one of its pole without division. If renal transplantation is to be done on kidney having multiple renal arteries, each artery of the donor kidney is to anastomosed to recipient's vessels. Compression of inferior vena cava by a loop of renal artery branches may lead to pooling blood below the level of renal arteries and leads to edema of lower limbs and syncopal attacks.

\section{Conclusion}

Knowledge of anatomy of renal blood supply is essential for good outcome following renal surgeries. Looping of renal artery branches around inferior vena cava is a rare presentation may cause syncope and bilateral pedal edema. Supernumerary renal vessels are common anomalies and the main importance of this abnormalities is as a source of potential error during operations in the retroperitoneum and on kidneys. Patients with this type of variations may be asymptomatic.

\section{References}

[1]. Susan standaring Gray's Anatomy. TheAnatomical Basis of Clinical practice.39thEdition London, Elseiver Churchil Living stone Publishers. 2005; $1274-75$

[2]. Campbell- Walsh, Urology $10^{\text {th }}$ edition-Wein,Kovoussi,

[3]. Bailey and Love short practice of Surgery $25^{\text {th }}$ edition. Williams,Bullstrode

[4]. SRB' Manual of surgery $3^{\text {rd }}$ edition Sriram Bhatt.M.

[5]. Fernandes RMP, Conte FHP, Favorito LA, Abidhu-Figueredo M, BabinskiMA. Triplerenal vein: an uncommon variation. Int J Morphol.2005;23:231-33.

[6]. Harrison LH, Flye MW, Seigler HF. Incidence of anatomical variants in renalvasculature in the presence of normal renal function. Ann Surg 1978;188(1):83-9.

[7]. Graves FT. The anatomy of the intra renal arteries and its Application to SegmentalResection of the kidney. Br J Surg 1954;42:13239.

[8]. Keibel F, Mall FP,eds.,Manual of human Embryology. Vol.2.Philadelphia, J.B.Lippincot 1912;820-825. 